\title{
Investigating the Association of Mental-Social Climate and Social Anxiety With Students' Self-Efficiency
}

\author{
Farideh Fallah ${ }^{1}$ and Asghar Nadi Ghara, \\ ${ }^{1}$ Department of Psychology and Social Sciences, Sari Branch, Islamic Azad University, Sari, IR Iran \\ ${ }^{2}$ Health Sciences Research Center, Mazandaran University of Medical Sciences, Sari, IR Iran \\ *Corresponding author: Asghar Nadi Ghara, Health Sciences Research Center, Mazandaran University of Medical Sciences, Sari, IR Iran. Tel: +98-1143543638, E-mail: statistic.nadi@gmail.com
}

Received: August 9, 2014; Revised: December 5, 2014; Accepted: December 21, 2014

\begin{abstract}
Background: The tendency and motivation to progress and achieve the ideal position have always encouraged people towards acquiring the required education.

Objectives: The present research aimed to investigate the association of mental-social climate and social anxiety with self-efficiency and also predict the academic self-efficiency of first grade high school students based on social anxiety and the mental-social climate of the classroom.

Materials and Methods: A total of 350 subjects (172 girls and 178 boys) have been chosen by a random clustering sampling form the first grade high school students of Qaemshahr, Iran. The academic self-efficiency questionnaire, the social anxiety scale for teenagers and the classroom mental climate scale were used to collect the required data. For data analysis, the statistical method of correlation analysis, independent $t$ test, and multivariate regression have been used.

Results: The research findings showed that there was a significant negative relationship between mental-social climate of the classroom and students' self-efficiency. In addition, social anxiety has been a significant negative relationship with self-efficiency. Furthermore, a significant positive relationship exists between mental-social climate and social anxiety.

Conclusions: In order to develop students' self-efficacy, there should be appropriate psychosocial climate. Therefore, teachers and administrators of education must provide all necessary arrangements to improve psychosocial climate classes.
\end{abstract}

Keywords: Anxiety; Climate; Efficiency

\section{Background}

The tendency and motivation to progress and achieve the ideal position have always persuaded people towards acquiring the required education. However, motivation is not the only prerequisite to get the intended situation but intelligence, ability, skill, knowledge, and so on are also the important factors. For example, a student who is worried and doubtful about his or her self-efficiency, ability, intelligence in the class climate, and feels an anxiety state. During the time of exams, especially the most important ones (e.g., entrance exam and final exams), most of the students experience the anxiety of exams. A little anxiety is natural and desirable and leads people to increase their effort and struggle; however, if it exceeds the average level, it may reduce academic achievement. A student who is anxious at test session feels that his or her mind is not working and has forgotten whatever learned so far. Such a person gives irrelevant, wrong, or imperfect answers to the questions and is involved in the consequences of the test with irrelevant and unwanted thoughts (1).

Some of these anxious states are related to the mentioned test and the others are irrelevant. If the level of the anxiety relates to the test content, the test's self-efficiency increases while the irrelevant anxiety with the assigned duty decreas- es the self-efficiency level (2). Bandura proposed the topic of self-efficiency. He defines self-efficiency as the person's judgment about his or her skills and capabilities for doing tasks in emergency situations when required. Self-efficiency affects someone's function only when he or she has the necessary skills for doing social job, and is excited enough for doing that job. On one hand, Bandura considers the feeling of self-efficiency as one of the most important effective constituents in self-regulation (apart from considering as a goal) (3). Therefore, self-efficiency has a lot of impacts on teenagers' education. Elias asserts academic self-efficiency as the student's trusting on his or her ability to succeed in difficult tasks (4). Arbona linked high level of academic self-efficiency with variables such as adjustment, success in school, and seeking help from others in academic problems (5). Crain also suggested that abilities are judged based on the physiological symbols and signs (6). Kim states that a significant relationship exists between psychological variables and mental well-being of the people (7).

The beliefs of self-efficiency are strongly associated with depression and anxiety. Social anxiety is an obvious and continuous fear of social situations. Or it is a function that may lead to embarrassment and being exposed to some

Copyright (C) 2015, Mazandaran University of Medical Sciences. This is an open-access article distributed under the terms of the Creative Commons Attribution-NonCommercial 4.0 International License (http://creativecommons.org/licenses/by-nc/4.0/) which permits copy and redistribute the material just in noncommercial usages, provided the original work is properly cited. 
immediate social and functional situations resulting in the reaction of anxiety (8). On one side, the mental and social climate of the students' classrooms and the degree of its relationship with the academic achievement are of the main concerns of the teachers, parents, and people involved in education. The class as a small and minor community consists of different people distinguished based on their experiences, cultures, and personality traits. These people bring their characteristics into the class and as a result, a different social and mental climate dominates the class (1). Accordingly, those who create such social and mental climate in the classroom are indeed the teacher and students whose purpose is teaching and learning. Thus, for teaching and learning, it is required to let desirable and favorable climate dominate the classrooms (9).

The present society is going forward with a rapid change and failure to adapt with its changes causes lack of compatibility in humans. In order to adapt oneself to the environment, both the environment and the self should be recognized. People's requirements and needs have to be investigated carefully. If we consider such changes in the process of knowledge, the institute, school, and university should take these changes into account. Today, one of the issues studied widely in psychology is the role of excitements and emotions. Anxiety can intensely influence the person's function. Therefore, understanding anxiety, its process and effects are necessary. It needs to point out that anxiety exists among people. Any intelligent being has anxiety, which is a natural state of the body. Various kinds of life aspects such as individual, social, and physical ones require our continuous adjustments. What drives us forward except anxiety? Every human thinks that he or she has some portion of anxiety. Generally, it can be said that $10 \%$ of anxieties for a normal human is necessary but unfortunately this percentage is not always low (10). School is one of the most important formal, social, and organized structures that flourishes children's body and mind in the society and makes them committed to and responsible for oneself, family, and the society by providing a healthy environment. In this regard, school setting creates a structure influencing a range of different emotions and in fact playing an effective role in creating different emotions $(11,12)$.

During the last two decades, self-efficiency, which was focused on teachers, trainers, and parents, was proposed as an important factor in education and training. This new element as an effective predictor in learning and motivating students can have an effective and significant role. If the students utilize the processes of self-efficiency, they can study more effectively and monitor how well they study (13). Ability and self-efficiency have direct and intense impact on the function and self-efficiency. They also have a direct and severe impact on self-efficiency that can modify the indirect effect of ability and the level on the function.

The image we have of our self-efficiency has a direct and intense impact on the levels of our anxiety. For example, in the experiments conducted by Zimmerman as the boys and girls were different in terms of self-efficiency, girls reported more anxiety (14). To what extent a person accurately estimates his or her behavior criteria, determines his or her personal self-efficiency. In the system of Bandura, the personal self-efficiency means the feelings of competence, efficiency, and capability to cope with life. Fulfilling and maintaining function's criteria increases personal self-efficiency and failure in realizing and sustaining those criteria leads to lowered personal selfefficiency (15). Anxiety is a form or state of agitation. Everybody would be anxiety-stricken, which is a pervasive, unpleasant, and vague agitation accompanied with the signs of the autonomic nervous system such as headache, perspiration, heartbeat, dyspnea, and mild stomachache. An anxious person might feel restless which presents as inability to sit and stand in one place for a long time. These signs are often different from person to person (16).

Freud believes that anxiety is the toll civilization takes on man today. It seems that in this so called civilized era, the problems of human are always complicating (1). Different researchers have noted that self-efficiency can be considered as a cognitive factor having a meditative role in the genesis of emotional problems (anxiety, and depression). It means that children and teenagers facing some negative and threatening events can manage them with their high self-efficiency that can protect them against anxiety. In other words, feeling low self-efficiency inhibits effective opposing or confronting skills and exposes the children and teenagers to the risk of developing anxiety signs and other emotional issues (17). According to Bandura, self-efficiency plays a pivotal role in self-regulating emotional states. In this sense, the received inability affects events and social conditions that influence the life of person significantly and helps to form futility and disappointment in the form of anxiety (17).

Furthermore, the students' classroom mental and social climate and its degree of relationship with academic achievement is one of the important topics that has been constantly be paid attention to by teachers, managers, and educational authorities. Understanding classroom mental and social climate can provide valuable feedback for teachers (18). Because classroom mental and social climate is effective in quitting school or studying, skipping classes, sadness and depression, students resisting against teachers, lack of comradeship among students, lack of satisfaction and interest in studying and learning (19). Many of the human behaviors are excited and controlled by the measures and functions of self-influence. Among the selfinfluence mechanisms, none of them is more important and pervasive than the belief in personal self-efficiency (1). Proposed the topic of self-efficiency, he defines selfefficiency as a person's judgment about ones skills and capabilities for doing tasks in the emergency situations that he requires. Self-efficiency affects someone's function only when he or she has the necessary skills for doing social task, and is excited enough for doing that task (1). The concept of believing self-efficiency was first used by Bandura to clarify human's behavior and it was defined as the belief 
in individual abilities for organizing and performing operational units in order to achieve certain goals. The concept of self-efficiency includes individual's effective, functional competence, and believing that successful activities will lead to certain results. If these beliefs are positive, they will result in developing behavioral intent.

Belief in self-efficiency is dynamic and changeable and the basis of individual differences when people match in terms of their knowledge. Its definition is based on 4 interactive main sources of information. These sources of information are as the following (2). Most of the time, fear and anxiety are considered with each other, though they are distinct. Fear depends on a known stimulus while anxiety is related to an unknown and indefinite stimulus. As for fear, the threatening stimulus is considerable and observable while in anxiety, the reason is unknown (1). Fear means a reaction against a real danger but anxiety means reaction against a danger that does not exist (10). "Building climate" at school is one of the important facilitating or preventive factors in human relationships. In this field, the dominant "enclosed" climate or an inapt one provides the reasons to be afraid of, including lack of trust, not expressing needs and problems, which lead to blocking the channels of communication and curbing talents and creativity. On the contrary, in an environment where there is a healthy climate on which people feel logical freedom, trust, possession and identity, and undoubtedly the grounds to exchange thoughts, the transfer of emotions and talents blooming are provided (20).

In the classroom, there is a set of different factors that go hand in hand and create an especial mental climate. If we take two adjacent classes or schools or almost close to each other in one academic level, being completely similar with respect to economic, social, and cultural conditions, we will understand that the dominating climate on them is different. In this case, although the physical condition of the classroom and the level of mental and emotional motivation and states of the learners are in turn effective in forming the classroom mental climate, the role of the teacher in making such climate is more important and determining. Because of this, the teacher himself should try to build a healthy mental climate in the classroom and to achieve this purpose, he should seek help from all factors involved in this issue (20). Classroom is a social setting. The presence and interaction of the students with their peers at this setting manifest their talents, problems, or their weaknesses. Also, their perception will decrease or increase. Mainhard et al. considered students' perceptions of their peers and the kind of existing relationship in the classroom as a social aspect of class environment and defined it as social climate referred to the relationships quality in the classroom (22). The interaction of class members with one another is mostly considered to be affected by the climate dominating the classroom. If the mental-social climate governing the classroom is filled with coherence and correlation, it may indicate the presence of discipline and assignment-orientation causing a confrontational and fric- tional climate that turns out to be like a competition (21). Based on the above mentioned issues, a research about selfefficiency, social anxiety, and mental and social climate of the classroom, which simultaneously investigate the effect of the main dimensions and factors of social anxiety and the classroom social and mental climate on self-efficiency could be a very valuable achievement in order to propose a suitable strategy to increase self-efficiency and as a result academic achievement. Investigating the classroom mental and social climate, social anxiety, and the academic self-efficiency can be a great help for teachers, parents, and educational authorities.

\section{Objectives}

The present research analyzes the relationships students understand their classroom dominating climate, social anxiety degree with students' academic self-efficiency level, and along with that the research predicts their academic self-efficiency. We also intend to determine which one of the social anxiety and the classroom mental and social climate variables plays a major role in predicting the academic self-efficiency.

\section{Materials and Methods}

The present research statistical population consists of all students of Qaemshahr first grade high school. The sample size was calculated according to the Cochran's formula, based on which for 3600 subject population with $\alpha$ as 0.05 and error of estimation (d) at 0.05, a sample consisting of 350 people was suggested. So, a total of 350 students were selected (172 girls and 178 boys). In order to choose the subjects, random and cluster sampling were used. First of all, there are 76 high schools in Qaemshahr, Iran (52 public schools and 24 non-public schools; 35 boys schools and 41 girls schools). The number of the students in the first grade of high school was 3613 out of whom 1838 were boys and 1775 were girls. Twelve high schools were studied by the researcher ( 6 girls' and 6 boys') and in each school; all first grade classes were chosen and evaluated.

\subsection{Instruments}

The social anxiety scale designed by La Gierca was used to evaluate the variable of social anxiety, which includes 18 items and 3 sub-scales of fear of negative evaluation, social anxiety and distress-new, social anxiety, and distress-general (1), and its validity was acceptable.

To evaluate students' educational self-efficiency the Morgan-jinks efficiency scale (1999) was used. This scale has 30 questions and includes 3 sub-scales of talent, effort, and context. The items of this scale, with Likert scale, have four answers. The creator of the scale declared the degree of inner homogeneity as 0.82 through the Cronbach $\alpha$ method. Also, the cronbach's alpha coefficients of the 3 sub-scales of talent, effort, and context were reported at $0.70,0.66$, and 0.78 , respectively (20). 
To examine the mental-social climate of a class, the My class inventory is used. This scale includes 20 items each of which being explained as statements. This scale includes 4 secondary dimensions or scales of friction, dependence, regularity, and competition. Hosseinchari et al., reported the validity and reliability of this scale as suitable (23).

\subsection{The Procedure}

So in order to measure the questionnaires reliability before conducting the research, 20 students, including 10 boys and 10 girls were selected as the primary sample. The Cronbach $\alpha$ coefficient for each scale is presented in Table 1. In order to analyze the collected data from the descriptive statistical indexes such as calculating the mean, standard deviation, and the like. Also, to analyze correlation, and answer the research questions regression, and independent $t$ test have been used. Meanwhile, in order to investigate the probability behind the role of mediating social anxiety between two concepts of mental-social climate and academic achievement, multivariate regression method has been applied.

\section{Results}

As it can be seen from Table 2, there are significant correlations between the variables of classroom mental-social climate, friction, coherence, discipline and competition, with the students' self-efficiency with the correlation coefficients of $-0.33,-0.042,-0.31,0.05$, and -0.07 , respectively, which indicates negative relationships. In this regard, there are significant negative relationships between variables of 'social anxiety,' 'fear of negative evaluation,' 'avoiding new situations' and then 'general situations' with academic self-efficiency with values of $-0.21,-0.033,-0.29$, and -0.0 , respectively, which means that whenever social anxiety increases, students' self-efficiency decreases. As it can be seen in Table 3, there is a significant relationship between the variables of classroom mental-social climate, friction, coherence, discipline and competition with social anxiety and the correlation coefficients are $0.33,0.37,0.06,0.02$, and 0.24 , respectively.

Now we try to answer this question: Which of the social anxiety and the classroom mental-social climate variables play a more important role in predicting self-efficiency dimensions and generally self-efficiency?

To this effect, the regression analysis was used. In this analysis, all dimensions of social anxiety and the classroom mental-social climate were included in the regression model and based on the standardized regression coefficient, Table 4 shows that which variable plays a more important role in predicting self-efficiency and its dimensions. So as you can see, the variables of 'fear of negative evaluation' and 'friction' are respectively the first and second priority and 'avoiding general situations' variable is the last priority. In order to study the difference between the means of the research, the main variables, and the dimensions of these variables between boys and girls, we used the independent t test. As it can be seen in Table 5, the mean discipline score is 3.02 in boys and 3.94 in girls where there is a significant difference $(\mathrm{P}<0.05)$. The mean 'fear of negative evaluation' score is 11.06 in boys and 15.20 in girls where there is significant difference $(\mathrm{P}<0.05)$. The mean 'endeavor' score is 20.41 in boys and 22.20 in girls, which has a significant difference $(\mathrm{P}<0.05)$. And the mean self-efficiency score is 50.45 in boys and 52.37 in girls where there is significant difference $(\mathrm{P}<0.05)$. The other variables are not significant.

\begin{tabular}{lc}
\hline Table 1. The Reliability of Each Variable of Used Questionnaires \\
\hline Variable & Cronbach's Alpha \\
\hline Friction & 0.77 \\
Coherence & 0.80 \\
Discipline & 0.80 \\
Competition & 0.84 \\
Fear of negative evaluation & 0.86 \\
Avoiding new situations & 0.81 \\
Avoiding general situations & 0.83 \\
Talent & 0.77 \\
Context & 0.84 \\
Endeavor & 0.85 \\
\hline
\end{tabular}

Table 2. Investigating the Relationship Between the Classroom Mental-Social Climate, Social Anxiety, and Its Dimension With the Students' Self-Efficiency a

\begin{tabular}{lcc}
\hline Variable & \multicolumn{2}{c}{ Students' Self-Efficiency } \\
\cline { 2 - 3 } & Pearson Correlation & Significance b \\
\hline Mental-social climate & -0.33 & 0.000 \\
Friction & -0.42 & 0.000 \\
Coherence & -0.31 & 0.000 \\
Discipline & 0.05 & 0.388 \\
Competition & -0.07 & 0.226 \\
General anxiety & -0.21 & 0.001 \\
$\begin{array}{l}\text { Fear of negative } \\
\text { evaluation }\end{array}$ & -0.33 & 0.000 \\
$\begin{array}{l}\text { Avoiding new } \\
\text { situations }\end{array}$ & -0.29 & 0.000 \\
$\begin{array}{l}\text { Avoiding general } \\
\text { situations }\end{array}$ & -0.04 & 0.490 \\
\hline $\begin{array}{l}\text { a Sample size was equal to 350. } \\
\text { b Values less than } 0.05 \text { are considered as significant. }\end{array}$ &
\end{tabular}

Table 3. Investigating the Relationship Between the Classroom Mental-Social Climate and the Students' Social Anxiety ${ }^{\mathrm{a}}$

\begin{tabular}{lcc}
\hline Variable & \multicolumn{2}{c}{ Social Anxiety } \\
\cline { 2 - 3 } Mental-social & Pearson Correlation & Significance \\
climate & 0.33 & 0.000 \\
Friction & 0.37 & 0.000 \\
Coherence & 0.06 & 0.192 \\
Discipline & 0.02 & 0.730 \\
Competition & 0.24 & 0.000 \\
\hline a Sample size was equal to 350. & \\
b Values less than 0.05 are considered as significant.
\end{tabular}


Fallah F et al.

\begin{tabular}{lcccccc}
\hline Table 4. Predicting Self-Efficiency Based on the Dimensions of the Classroom Mental-Social Climate and Social Anxiety \\
\hline & $\mathbf{R}^{\mathbf{2}}$ & Adjusted $\mathbf{R}^{\mathbf{2}}$ & Beta Standard & T-Value & Significance & Prioritization \\
\hline Dependent variable of self-efficiency & 0.53 & 0.46 & & & & \\
Friction & & & -0.27 & -3.62 & 0.000 & 2 \\
\hline Coherence & & -0.06 & -3.36 & 0.000 & 4 \\
Discipline & & -0.07 & -0.991 & 0.322 & 5 \\
\hline Competition & & -0.06 & -0.803 & 0.422 & 6 \\
\hline Fear of negative evaluation & & -0.31 & -4.46 & 0.000 & 1 \\
Avoiding new situations & & -0.25 & -3.54 & 0.000 & 3 \\
Avoiding general situations & & 0.03 & 0.571 & 0.568 & 7 \\
\hline
\end{tabular}

${ }^{\mathrm{a}}$ Values less than 0.05 are considered as significant.

Table 5. T-Test, Comparing the Means of Dimensions of the Classroom Mental-Social Climate, Social Anxiety, and the Self-Efficiency Between Boys and Girls

\begin{tabular}{|c|c|c|c|c|c|}
\hline Group & No. & Values of Dimensions ${ }^{a}$ & $\mathbf{t}$ & d.f. & Significance $^{b}$ \\
\hline \multicolumn{6}{|l|}{ Mental Climate } \\
\hline Friction & & & -0.2478 & 348 & 0.804 \\
\hline Girl & 172 & $3.21 \pm 1.67$ & & & \\
\hline Boy & 178 & $3.29 \pm 1.18$ & & & \\
\hline Coherence & & & 0.7744 & 384 & 0.439 \\
\hline Girl & 172 & $5.36 \pm 2.49$ & & & \\
\hline Boy & 178 & $5.11 \pm 1.79$ & & & \\
\hline Discipline & & & 2.8498 & 333.94 & 0.004 \\
\hline Girl & 172 & $3.94 \pm 1.27$ & & & \\
\hline Boy & 178 & $3.02 \pm 2.13$ & & & \\
\hline Competition & & & -1.0532 & 384 & 0.292 \\
\hline Girl & 172 & $5.22 \pm 2.59$ & & & \\
\hline Boy & 178 & $5.56 \pm 2.18$ & & & \\
\hline \multicolumn{6}{|l|}{ Social Anxiety } \\
\hline Fear of negative evaluation & & & 6.8184 & 333.971 & 0.000 \\
\hline Girl & 172 & $15.20 \pm 5.51$ & & & \\
\hline Boy & 178 & $11.06 \pm 4.32$ & & & \\
\hline Avoiding new situations & & & -5.1056 & 332.261 & 0.000 \\
\hline Girl & 172 & $16.60 \pm 4.35$ & & & \\
\hline Boy & 178 & $19.47 \pm 6.01$ & & & \\
\hline Avoiding general situations & & & 0.146 & 348 & 0.884 \\
\hline Girl & 172 & $11.26 \pm 4.23$ & & & \\
\hline Boy & 178 & $11.20 \pm 3.41$ & & & \\
\hline General anxiety & & & -0.547 & 348 & 0.584 \\
\hline Girl & 172 & $41.00 \pm 4.66$ & & & \\
\hline Boy & 178 & $41.27 \pm 4.57$ & & & \\
\hline \multicolumn{6}{|l|}{ Self-Efficiency } \\
\hline Talent & & & 1.061 & 333.942 & 0.219 \\
\hline Girl & 172 & $18.69 \pm 5.87$ & & & \\
\hline Boy & 178 & $18.10 \pm 4.46$ & & & \\
\hline Context & & & -1.420 & 348 & 0.156 \\
\hline Girl & 172 & $11.48 \pm 2.98$ & & & \\
\hline Boy & 178 & $11.94 \pm 3.06$ & & & \\
\hline Endeavor & & & 5.5447 & 333.942 & 0.000 \\
\hline Girl & 172 & $22.20 \pm 4.57$ & & & \\
\hline Boy & 178 & $20.41 \pm 5.63$ & & & \\
\hline Self-efficiency & & & 5.9474 & 348 & 0.000 \\
\hline Girl & 172 & $52.37 \pm 4.47$ & & & \\
\hline Boy & 178 & $50.45 \pm 4.38$ & & & \\
\hline
\end{tabular}

\footnotetext{
$\mathrm{a}$ Values are presented as mean $\pm \mathrm{SD}$.

b Values less than 0.05 are considered as significant.
} 


\section{Discussion}

The present study shows that there is a significant negative relationship between the general classroom mentalsocial climate and the students' self-efficiency. In other words, increasing the classroom mental-social climate decreases the degree of students' self-efficiency. After studying the association of self-efficiency and its dimensions with social anxiety, the results suggest that there is a significant negative relationship between self-efficiency and social anxiety in general sense. With regard to the relationship between social anxiety and the classroom mental-social climate, the results indicate that there is a significant positive relationship between social anxiety and the classroom mental-social climate. Other studies have reported the same results $(1,2,20)$.

Finally, regression analysis results demonstrated that the dimensions of 'fear of negative evaluation,' 'friction,' and 'avoiding new situations' have the biggest share and 'avoiding general situations' and 'competition' have the smallest share in predicting the students' self-efficiency. Other studies have reached the same results $(1,2)$. The results suggest that there is a significant difference among the acquired means in dimensions of 'discipline,' 'fear of negative evaluation,' 'avoiding new situations,' 'endeavor' and self-efficiency between boys and girls, and there was no significant difference in other dimensions. Results show that 'discipline,' 'fear of negative evaluation,' 'endeavor' and self-efficiency among girls are higher than those in boys and 'avoiding new situations' in boys is higher than that in girls. Some other studies have obtained the same results $(20,23)$.

Research findings highlighted that there is a significant negative relationship between the classroom mentalsocial climate and the students' self-efficiency. Khaje and Hosseinchari (1) and Dadsetan (2) obtained the same results in their studies. To justify this finding, it can be said that in classes with a more suitable mental climate students believe more in themselves and accordingly their academic function improves. Findings also revealed that there is a reverse relationship between social-anxiety and self-efficiency, which is generally due to effects of social anxiety on the students; these effects destroy self-confidence and lower the person's self-efficiency. It is worth mentioning that Khaje and Hosseinchari (1) got the same results . All these findings are highly compatible with the conducted research cases in this field, which other studies confirmed them $(1,2)$. Findings proved that there is a negative relationship between social anxiety and the classroom mental-social climate and an increase in social anxiety and its dimensions decreases the effective factors on the classroom mental-social climate. Fraser obtained the same results in his study (21). To explain this finding, it can be said that the main factors in creating the mental-social climate in the classroom are closely related to the social anxiety factors.

In studying the existing difference between boys and girls, the results showed that there is a significant relationship between boys and girls in terms of the mean of self-efficiency, and the mean of self-efficiency in girls is more than that in boys and among the dimensions of self-efficiency, the dimension of 'endeavor' in girls is also more than that in boys and this difference is significant. Lawrenz (24) and Byrne et al. (25) obtained the same results in their studies. To explain this finding, it can be said that girls usually try more in achieving their goals and by taking this fact into consideration that girls have more mental maturity than boys in the first grade, such results seem natural. Among the dimensions of mental-social climate of the classroom, just in the dimension of 'discipline,' there is a meaningful relationship between boys and girls and it is more among girls than the boys. This result seems completely logical based on the personality characteristics of the boys. There is a significant difference between boys and girls in just 'fear of negative evaluation' and 'avoiding new situations' from the dimensions of the social anxiety. And the 'fear of negative evaluation' is higher in girls than the boys, which is justifiable based on this fact that girls are more sensitive in being judged by others than boys and they like to attract more attention. 'Avoiding new situations' among boys is less than girls. This result, which is to some extent acceptable, is based on boys' more tendency towards friends and being among their acquaintances and friends.

\section{Authors' Contributions}

Both authors conceived and designed the evaluation and drafted the manuscript. Farideh Fallah collected the clinical data. Asghar Nadi Ghara interpreted the clinical data and performed the statistical analysis. Both authors revised the manuscript, read, and approved the final manuscript.

\section{Declaration of Interest}

None declared.

\section{References}

1. Khaje L, Hosseinchari M. Investing the relationship between social anxiety and classroom psychosocial climate with academic self-efficacy in junior high school students. J Educ Psychol. 2012;7(20):131-53.

2. Dadsetan P. Social anxiety disorder and drama therapy. Developmental psychology (psychologists Iran). psychologists Iran. 2008;4(14):115-23.

3. Bandura A. Perceived self-efficacy in cognitive development and functioning. . Educational Psychologist. 1993;28(2):117-48.

4. Elias R.Z. Anti-Intellectual Attitudes and Academic Self-Efficacy Among Business Students. Journal of Education for Business. 208;84(2):2008.

5. Arbona C. Handbook of Counseling psychology. New York: Wiley; he development of academic achievement in school-aged children: Precursors to career development. In S. D. Brown \& R. W. Lent (Eds.) pp. 435-70.

6. Crain W. Theories of Development: Concepts and Applications, 4th ed. 2000 London.

7. Kim A, Park I. Hierarchical structure of self- efficacy in terms of generality Levels and its relations to academic performance: 
general, academic, and subject specific Self- efficacy, paper presented at the annual meeting of the Ame ican Educational Research Association, April, 2000, New Orleans.

8. American Psychiatric Association. Diagnostic and statistical manual of mental disorders (DSM). Washington, DC: American psychiatric association; 1994.

9. Fraser BJ, Fisher DL. Predicting Students Outcomes From Their Perception Of Classroom Psychology Environment. Am Educ Res J.1982;20:191-20.

10. Khodabakhshi M. Identifying the relationship between mental health and spiritual intelligence. Lorestan Univ Med Sci. 2014;16(1):58-65.

11. Zimmerman BJ, Bandura A. Impact of self-regulatory influences on writing course attainment. Am Educ Res J. 1994;31(4):845-62.

12. Ziegler SM. Theory- directed nursing practice (2nd ed). New York: Springer; 2005.

13. Moradi M, Jafari SE, Abed M. Happiness and personality Review. Events Cogn Sci. 2004;7(2):60-71.

14. Zimmerman BJ. Attaining self-regulation: A social cognitive perspective. In: Boekaerts M, Pintrich PR, Zeidner M, editors. Handbook of self-regulation. San Diego: Academic Press; 2000. pp.13-39.

15. Caprara GV, Barbaranelli C, Steca P, Malone PS. Teachers' selfefficacy beliefs as determinants of job satisfaction and students' academic achievement: A study at the school level.J Sch Psychol. 2006;44(6):473-90.

16. Kaplan H, Sadvk B. [Summary of Clinical Psychiatry Volume I, II and
III]Translated by Rafie, H. and foster, F. Tehran: Venerable;

17. Mone MA, Baker DD, Jeffries F. Predictive validity and time dependency of self-efficacy, self-esteem, personal goals, and academic performance. Educ Psychol Meas. 1995;55(5):716-27.

18. Britner SL, Pajares F. Self-efficacy beliefs, motivation, race, and gender in middle school science. J Women Minor Sci Eng. 2001;7(4):271-85.

19. Mellings TM, Alden LE. Cognitive processes in social anxiety: the effects of self-focus, rumination and anticipatory processing. $\mathrm{Be}$ hav Res Ther. 2000;38(3):243-57.

20. Atoofi Salmani M. The effect of psychological and social - class of fifth grade elementary student achievement in Kashan city.J Mod Thoughts Educ. 2008;1:63-82.

21. Fraser BJ. Research on Classroom and School Climate In D. Gabel Handbook of research on science teaching and learning. New York: Mlacmillan; 1994. pp. 493-542.

22. Mainhard M. T, Brekelmans M, Wubbels T. Coercive and Supportive Teacher Behavior: Within- and across-lesson associations with the clas room social climate. Social and Behavioural Sciences, Utrecht University, 2010, 1-10.

23. Hosseinchari M, Khayer M. Classroom psychosocial climate as a component of school culture. J Educ Psychol. 2003;9(3-4):25-42.

24. Lawrenz F. Gender effects for student perception of the classroom psychosocial environment. J Res Sci Teach. 1987;24(8):689-97.

25. Byrne D, Clore GL, Smeaton G. The attraction hypothesis: Do similar attitudes affect anything? J Pers Soc Psychol. 1986;51:1167-70. 